\title{
RAZVOJ PREBIVALSTVA V LJUBLJANSKI URBANI REGIJI
}

\author{
Dejan Rebernik \\ Oddelek za geografijo, Filozofska fakulteta, Univerza v Ljubljani, \\ Aškerčeva 2, 1000 Ljubljana, Slovenija \\ e-mail : dejan.rebernik@guest.arnes.si
}

\begin{abstract}
Izvleček
$\mathrm{V}$ prispevku so predstavljene osnovne značilnosti razvoja prebivalstva in urbanizacijskih procesov v Ljubljani in Ljubljanski mestni regiji. Do konca sedemdesetih let je bila prebivalstvena rast posledica močnega priseljevanja iz Slovenije in preostale Jugoslavije. V osemdesetih in devetdesetih letih nastopi dekoncentracija prebivalstva znotraj regije in depopulacija mestnega središča Ljubljane. V zadnjih desetih letih so najhitrejšo rast prebivalstva zabeležila razpršena ruralna naselja v podeželskem delu regije, v posameznih delih mestnega središča pa poteka reurbanizacija in gentrifikacija.
\end{abstract}

Ključne besede: razvoj prebivalstva, urbanizacija, suburbanizacija, eksurbanizacija, counterurbanizacija, Ljubljana, Ljubljanska mestna regija

\section{POPULATION DEVELOPMENT IN LJUBLJANA URBAN REGION}

\begin{abstract}
The paper presents the main characteristic of population development and urbanisation processes in Ljubljana and Ljubljana urban region. Up to the end of the seventies fast population growth was a consequence of strong immigration from rural parts of Slovenia and the rest of Yugoslavia. In the eighties and nineties deconcentration of population within the region with intense suburbanisation and depopulation of inner city and older residential neighbourhoods were the main urbanisation processes. In the second half of the nineties the highest population growth was recorded in dispersed rural settlements in the periphery of the region. In some parts of the inner city reurbanisation and gentrification occurred.
\end{abstract}

Key words: population development, urbanisation, suburbanisation, exurbanisation, counterurbanisation, Ljubljana, Ljubljana urban region. 


\section{UVOD}

Ljubljana in njena urbana regija sta po letu 1945 doživljali zelo dinamičen prebivalstveni razvoj. Do konca sedemdesetih let je bila prebivalstvena rast predvsem posledica priseljevanja iz ruralnih in manj razvitih delov Slovenije in preostale Jugoslavije. Priseljenci so zagotavljali delovno silo za industrijo in storitve. Za to obdobje je značilna koncentracija prebivalstva $v$ Ljubljani in satelitskih mestih $v$ regiji. $V$ osemdesetih in devetdesetih letih se okrepi razseljevanje prebivalstva $\mathrm{v}$ obmestna naselja. Na ta način se oblikuje največje območje suburbanizacije v Sloveniji z okoli 150.000 prebivalci. Mestno središče in starejša stanovanjska območja zajame depopulacija.

Po letu 1991 doživi Ljubljanska urbana regija hiter gospodarski razvoj, kar privlači nove migracijske tokove. Regija ima najvišji migracijski saldo med vsemi slovenskimi regijami. Po letu 1995 imajo najhitrejšo prebivalstveno rast manjša ruralna naselja v podeželskem delu regije. S suburbanizacijo postopno prehaja v eksurbanizacijo oziroma counterurbanizacijo. Najnovejši razvoj prebivalstva $v$ regiji ima tako vse značilnosti in negativne učinke pojava »urban sprawl«. V posameznih delih Ljubljane se okrepita procesa reurbanizacije in gentrifikacije.

Osnovni cilj prispevka je prikazati glavne značilnosti razvoja prebivalstva in urbanizacijskih procesov v Ljubljanski mestni regiji. Kratki predstavitvi urbanizacijskih trendov v Sloveniji sledi oris razvoja prebivalstva v regiji do leta 1991. V nadaljevanju so podrobneje predstavljeni novejši urbanizacijski procesi in njihovi poglavitni prostorski, gospodarski in okoljski učinki.

\section{URBANIZACIJSKI PROCESI V SLOVENIJI}

Za Slovenijo je v primerjavi z drugimi evropskimi državami značilna relativno nizka stopnja urbanizacije, le nekaj nad $50 \%$. Kljub temu je za petdeseta, šestdeseta in sedemdeseta leta značilna hitra urbanizacija, saj se je delež mestnega prebivalstva povečal od $26 \%$ leta 1948 na $36 \%$ leta 1961, $45 \%$ leta 1971 in $49 \%$ leta 1981. Povprečne letne stopnje rasti mestnega prebivalstva so v obdobju 1961 - 1971 znašale $2.15 \%$ in v obdobju $1971-1981$ $2.05 \%$, medtem ko je skupno prebivalstvo narǎčalo po letni stopnji $0.6 \%$ v prvem in $1.1 \%$ v drugem obdobju (Ravbar, 1989). Urbanizacija je bila predvsem posledica deagrarizacije in industrijalizacije ter priseljevanja prebivalstva $v$ mesta iz ruralnih območij Slovenije in ostale Jugoslavije. Prebivalstvo je najhitreje naraščalo v večjih regionalnih središčih kot so Ljubljana, Maribor, Celje, Kranj, Koper in Novo mesto in v izrazito industrijskih mestih kot na primer Jesenice, Trbovlje in Tržič. Nastali sta tudi dve novi mesti, Nova Gorica in Velenje. V sedemdesetih letih so najhitrejšo rast zabeležila manjša mesta v urbaniziranem zaledju Ljubljane, Maribora in Celja. Ob tem pa je potrebno poudariti, da je bila urbanizacija v Sloveniji manj izrazita kot v drugih jugoslovanskih republikah. Razmeroma šibka urbanizacija v Sloveniji je predvsem posledica intenzivnih dnevnih migracij delovne sile iz podeželskih naselij v urbana zaposlitvena središča in začetka izvajanja politike policentrič- 
nega gospodarskega in urbanega razvoja. Policentrizem je v Sloveniji v sedemdesetih in osemdesetih letih postal osnovni koncept prostorskega razvoja. Spodbujal se je razvoj industrije in storitev v manjših urbanih in ruralnih naseljih ter v manj razvitih delih Slovenije. Dostop do delovnih mest na podeželju je upočasnil ruralno - urbane migracije.

Po letu 1981 je opazna počasnejša rast mestnega prebivalstva. Do leta 1991 se je stopnja urbanizacije dvignila na $51 \%$, povprečna letna stopnja rasti mestnega prebivalstva pa je znašala le še $0.8 \%$, ob tem da je celotno prebivalstvo naraščalo po $1 \%$ letni stopnji (Ravbar, 1995). Medtem ko je prebivalstvo $\mathrm{v}$ večini mest še naraščalo, se v osemdesetih letih prvič pojavi upadanje prebivalstva v nekaterih mestih. Prebivalstvo izgubljajo večja mesta $v$ bolj urbaniziranih regijah, še nadalje pa rastejo manjša mesta v manj urbaniziranih delih države.

Očitno je torej, da je v osemdesetih letih klasična urbanizacija s procesom koncentracije prebivalstva $\mathrm{v}$ mestih prešla $\mathrm{v}$ (sub)urbanizacijo širših zgostitvenih območij okoli večjih mest. Na račun razseljevanja mestnega prebivalstva so imela $v$ osemdesetih letih najvišjo stopnjo rasti prebivalstva obmestna naselja $\mathrm{v}$ okolici večjih regionalnih središč. Proces suburbanizacije je tako zajel predvsem širša urbanizirana območja okoli Ljubljane, Maribora in Celja, v manjši meri pa tudi okoli Kranja, Kopra, Nove Gorice in Novega mesta.

$\mathrm{V}$ devetdesetih letih so se omenjeni procesi še okrepili. Skupno število prebivalcev v mestih se je zmanjšalo, najbolj izrazito v večjih središčih. Med leti 1996 in 2002 so v absolutnih vrednostih največ prebivalcev izgubila mesta Maribor (-6000), Ljubljana(-5900), Jesenice (-4300), Nova Gorica (-1200), Celje (-1100) in Murska Sobota (-1000). Delež prebivalcev, ki živijo v mestnih naseljih, se je tako med leti 1996 in 2002 zmanjšal za $1 \%$ (Černe, 2003). Hkrati se je nadaljevala in okrepila dekoncentracija prebivalstva v širših suburbaniziranih območijh. $\mathrm{V}$ prvi polovici devetdesetih je bila rast prebivalstva najhitrejša v suburbaniziranih obmestnih naseljih, med leti 1996 in 2002 pa so imela najhitrejšo rast majhna podeželska naselja $\mathrm{z}$ dobro dostopnostjo do večjih urbanih središč. V zadnjem obdobju je torej v Sloveniji prišlo do urbanizacije širšega podeželskega zaledja urbanih regij. $\mathrm{V}$ prispevku bomo na primeru Ljubljanske urbane regije poskušal ugotoviti, ali gre pri tem za prehod iz suburbanizacije $\mathrm{v}$ urbanizacijo podeželja oziroma counterurbanizacijo.

\section{RAZVOJ PREBIVALSTVA IN ZNAČILNOSTI POSELITVE $\checkmark$ LJUBLJANSKI URBANI REGIJI DO LETA I99I}

Današnje število in prostorska razporeditev prebivalstva v Ljubljanski urbani regiji je predvsem rezultat migracijskih gibanj, ki so potekala v Sloveniji in tudi nekdanji Jugoslaviji po letu 1945. Čeprav je za Slovenijo še danes značilna relativno nizka stopnja urbanizacije, ki dosega le nekaj čez $50 \%$ prebivalstva, pa je za prvo povojno obdobje do konca sedemdesetih let značilna pospešena urbanizacija, ki se je napajala pretežno s poudarjenimi migracijami prebivalstva s podeželja (Ravbar, 1994). Prebivalstvo se je priseljevalo iz slovenskega podeželja, velik del, približno eno tretjino pa predstavljajo migranti iz območij nekdanje Jugoslavije. Tako se je prebivalstvo na območju današnje Mestne občine Ljubljana poveča- 
lo od 123000 leta 1948 na 265000 leta 1981 (Rebernik, 1999). V tem obdobju so hitro rasla tudi nekatera večja mestna naselja, zlasti Domžale, Vrhnika, Litja in Grosuplje.

Rast prebivalstva $\mathrm{v}$ mestih je posledica naravnega prirastka mestnega prebivalstva in priseljevanja v mesto. V Ljubljani je vse do leta 1981 večji del rasti prebivalstva posledica priseljevanja $\mathrm{v}$ mesto. Več kot dve tretjini prirastka tako lahko pripišemo pozitivnemu migracijskemu saldu. Med leti 1945 in 1964 se je v mesto Ljubljana priselilo 46779, v mestu pa je bilo rojenih le 26628 oseb. Na območje petih ljubljanskih občin se je med leti 1965 in 1980 priselilo 57198, rojenih pa je bilo 41171 oseb. To dokazuje, da je osnovni vzrok za hitro rast prebivalstva med leti 1945 in 1980 migracija prebivalstva iz podeželja v mesto, da pa se je delež naravnega prirastka v skupni rasti prebivalstva postopoma povečeval. Tako je v sedemdesetih letih letni naravni prirastek že dosegel migracijski saldo in ga po letu 1979 tudi presegel. Med leti 1980 in 1993 pa je od skupnega prirastka, ki je dosegel 18462 prebivalcev, na migracijska gibanja odpadlo le še 409 prebivalcev. Pri tem je potrebno opozoriti, da je bilo priseljevanje, posebno iz republik bivše Jugoslavije, prisotno tudi po letu 1980. Hkrati se je začelo intenzivno odseljevanje mestnega prebivalstva $v$ okoliška obmestna naselja, ki je leta 1989 prvič preseglo priseljevanje. Tako sta $\mathrm{v}$ osemdesetih letih hkrati potekala dva procesa : suburbanizacija ljubljanskega obmestja z razseljevanjem mestnega prebivalstva in "klasična" urbanizacija s priseljevanjem prebivalstva iz manj razvitih območij Slovenije in nekdanje skupne države.

Ob splošnem hitrem naraščanju prebivalstva $\mathrm{v}$ Ljubljani pa je bila dinamika gibanja prebivalstva po posameznih delih mesta zelo različna. V prvem povojnem obdobju, med leti 1948 in 1953, je imela najhitrejšo prebivalstveno rast Šiška, kjer so bili zgrajeni prvi stanovanjski bloki. Število prebivalcev se je občutno povečalo tudi v mestnem središču, kjer so ob povojnem pomanjkanju stanovanj priseljence in vojne begunce naselili v nacionalizirana meščanska stanovanja in vile. Obdobje med leti 1951 in 1961 označuje hitra rast prebivalstva, ki je bila v prvi vrsti posledica močnega priseljevanja v mesto. Prebivalstvo je skokovito poraslo za Bežigradom, močno pa tudi v Šiški, Mostah in na Viču, kar je predvsem posledica gradnje blokovskih sosesk. Hitro rast so dosegla tudi številna obmestna naselja, predvsem v severnem delu obmestja, ki jih je zajela urbanizacija. Za čas med leti 1961 in 1971 je značilna relativno največja rast prebivalstva, ki se je povečalo kar za $28 \%$. Zelo se poveča število prebivalcev v mestnih predelih Moste, Bežigrad in Vič-Rudnik, kar je posledica intenzivne gradnje stanovanjskih blokov in stolpnic. Mestno središče preide $\mathrm{v}$ depopulacijo oziroma citizacijo. Med leti 1971 in 1981 se je težišče rasti prebivalstva se z okrepljeno individualno gradnjo enodružinskih hiš oziroma pričetkom procesa suburbanizacije premaknilo v severna, zahodna in vzhodna obmestna naselja, medtem ko je za južno obrobje mesta značilna stagnacija prebivalstva. $\mathrm{V}$ mestnem središču pa se depopulacija in citizacija še okrepita, saj se v mestnem središču število prebivalcev zmanjša kar za 20 \%. Po letu 1981 se rast prebivalstva močno umiri in do leta 1991 naraste le še za $3 \%$. Upadanje števila prebivalstva se nadaljuje v večjem delu mestnega središča, zajelo pa je tudi starejša predmestja, predvsem starejše blokovske soseske. Prebivalstvo še nadalje narašča na celotnem mestnem obrobju.

Razvoj prebivalstva na preostalem območju današnje Ljubljanske urbane regije je bil v obdobju do leta 1971 precej bolj umirjen kot v Ljubljani. Izjema so manjša satelitska mesta 
in urbanizirana naselja v zaledju Ljubljane, predvsem Domžale, Vrhnika, Medvode, Litija in Grosuplje. Po letu 1971 pa se je na račun močno povečanega priseljevanja prebivalstvena rast močno okrepila v ožjem suburbanem obmestju Ljubljane, predvsem v severnih in zahodnih obmestnih naseljih. V desetletju med leti 1981 in 1991 so na račun suburbanizacije oziroma razseljevanje prebivalstva iz Ljubljane izjemno rast prebivalstva doživela naselja $\mathrm{v}$ ožjem suburbanem pasu okoli Ljubljane, predvsem v severnem delu med Ljubljano, Domžalami in Kamnikom ter v pasu na severnem obrobju Ljubljanskega barja. V desetletju med 1981 in 1991 so tako naselja v suburbanem pasu okoli Ljubljane narasla za 20\% do 60\% (Ravbar, 1994). Okoli Ljubljane se je tako oblikovalo največje suburbanizirano območje v Sloveniji. Leta 1991 je obsegalo tretjino ozemlja današnje Ljubljanske urbane regije z okoli 150.000 prebivalci.

$\mathrm{V}$ regiji so se tako oblikovale tri značilne oblike poselitve : mesta (Ljubljana in satelitska mesta), urbanizirana in gosto naseljena območja v ožjem gravitacijskem zaledju Ljubljane in redkeje poseljena podeželska območja. Za območja suburbanizacije je značilna razpršena individualna stanovanjska gradnja, ki jo omogoča liberalen in relativno poceni nakup zemljišč in nizki stroški komunalne opremljenosti. V času socializma predstavlja individualna gradnja tudi edino možnost vlaganja prihrankov, saj druge oblike investiranja niso bile možne. Razmah avtomobilizma in s tem izboljšana prometna dostopnost omogoča dnevne delovne migracije, saj zaposlitev ostaja skoncentrirana v mestih.

Osnovni razlogi in pogoji za razmah suburbanizacije v Sloveniji v sedemdesetih in osemdesetih letih so: pomanjkanje in visoke cene stanovanj ter zemljišč $v$ mestih in na drugi strani relativni nizke cene zemljišč ter komunalnih priključkov na obrobju mest, želja po bivanju v enodružinskih hišah, bolj kvalitetno bivalno okolje, vlaganja dohodkov v stanovanjsko gradnjo, razmah osebnega avtomobilskega prometa, gradnja cest in s tem izboljšana prometna dostopnosti do naselij v zaledju mest, neučinkovito urbanistično načrtovanje in nadzor.

V slovenskih razmerah suburbanizacijo spremlja intenzivna morfološka in socialna preobrazba obmestnega prostora, saj gre za urbanizacijo nekdanjih ruralnih naselij. Ravbar tako suburbanizacijo v Sloveniji definira kot širjenje sodobnih naselij z manjšo gostoto poselitve v vplivnem območju mest (Ravbar, 1997). Nov in uniformiziran tip urbane enodružinske hiše je v ostrem nasprotju s tradicionalno ruralno arhitekturo. Zaradi nedorečene urbanistične politike je gradnja stihijska, kar se kaže v zelo razpršeni poselitvi. Deloma gre za povečevanje in preobrazbo obstoječih ruralnih naselij, deloma pa se pojavljajo nova območja poselitve, kot na primer obcestna poselitev in zraščanje sosednjih naselij, manjše skupine novih stanovanjskih hiš ali povsem izolirane lokacije. Postopoma se poselitev v območjih suburbanizacije zgosti. Tako se ob glavnih prometnicah oblikujejo strnjeni pasovi poselitve v obliki enodružinskih hiš, v primeru Ljubljanske urbane regije na primer med Ljubljano, Domžalami in Kamnikom ter v smeri proti Vrhniki in Škofljici. Suburbanizacija tako pomeni trajno izgubo in potratno rabo zemljišč, povečan promet in visoke stroške izgradnje in vzdrževanja komunalne in energetske infrastrastrikture.

Socialna preobrazba suburbaniziranih naselij se kaže v visokem deležu priseljenega prebivalstva in visokem deležu dnevnih migrantov. Za suburbana naselja je tako značilna pretežno bivalna funkcija $\mathrm{z}$ malo delovnimi mesti in razmeroma slaba opremljenost $\mathrm{z}$ oskr- 
bnimi in storitvenimi dejavnostmi. Delovna mesta ostanejo skoncentrirana v mestih. Intenzivne dnevne migracije se odražajo $\mathrm{v}$ povečanih prometnih tokovih in porastu deleža osebnega avtomobilskega prometa.

Delež agrarnega prebivalstva se je $\mathrm{v}$ območjih suburbanizacije postopno zniževal, tako da je do leta 1991 v večini takih območij padel pod $5 \%$ aktivnega prebivalstva. V podeželskih območjih, ki jih suburbanizacija ni zajela, je ostal delež agrarnega prebivalstva precej višji. Med kmečkimi gospodarstvi prevladujejo mešana delavsko kmečka gospodinjstva. Nekdanja podeželska območja okoli urbanih središč tako postanejo bivalni prostor za neagrarno prebivalstvo z urbanim načinom življenja. Urbani način življenja in vrednote se tako razširijo na široka suburbanizirana območja.

\section{RAZVOJ PREBIVALSTVA IN URBANIZACIJSKI TRENDI V LJUBLJANSKI URBANI REGIJI PO LETU I99।}

Ljubljanska urbana regija tudi po letu 1991 ostaja izrazito območje priseljevanja prebivalstva. Za Slovenijo v celoti so značilne relativno šibke medregionalne migracije prebivalstva. Ljubljanska urbana regija ima med vsemi statističnimi regijami najvišji selitveni prirast. Med leti 1991 in 2002 se je tako število prebivalcev v celotni regiji povečalo za $5.5 \%$. Zanimivo je, da je velik del priseljenega prebivalstva iz tujine, kar kaže na ponovno krepitev priseljevanja v Slovenijo, zlasti v Ljubljansko urbano regijo. Priseljevanje je povezano predvsem z zaposlitvijo, saj Ljubljanska urbana regija beleži najhitrejšo rast in najpestrejšo strukturo delovnih mest ter najugodnejše razvojne trende. Dejanski obseg priseljevanja je še precej večji, saj veliko oseb ob selitvi ne prijavi menjave stalnega bivališča.

Tudi po letu 1991 se v Ljubljanski urbani regiji nadaljuje intenzivna suburbanizacija. Raz-seljevanje prebivalstva iz Ljubljane v suburbanizirano obmestje se še okrepi, saj se v mestu Ljubljana število prebivalcev med leti 1991 in 2002 zmanjša za 9.000 oziroma 3.5 \%. $\mathrm{V}$ ostalih manjših mestnih naseljih prebivalstvo še nadalje narašča, toda z nizko stopnjo rasti.

Takšne migracijske trende potrjujejo tudi podatki o selitvenem gibanju prebivalstva za leto 2003. Mestna občina Ljubljana ima negativni selitveni saldo (3802 priseljenih in 4999 odseljenih). Vse ostale občine v Ljubljanski urbani regiji so imele pozitiven migracijski saldo. Posebno velik selitveni prirast izkazujejo občine Domžale, Grosuplje, Ivančna Gorica, Medvode, Škofljica in Trzin.

Po letu 1991, še posebno v drugi polovici devetdesetih let, je najhitrejša rast prebivalstva značilna za manjša ruralna naselja. V primerjavi z obdobjem 1981 do 1991 se je torej območje naraščanja prebivalstva prostorsko razširilo iz ožjega in gosto poseljenega obmestja tudi na podeželska območja v regiji. Nova poselitev na podeželju je izrazito razpršena, pogosto izven ali na obrobju obstoječih ruralnih naselij. Pojav ima vse značilnosti procesa »urban sprawl«. Gre izključno za novogradnje v obliki enodružinskih hiš, najpogosteje za »individualno samogradnjo«. Novogradnje se locirajo posamično ali v manjših skupinah. Kot del tega procesa je za regijo značilna tudi preobrazba naselij sekundarnih počitniških hiš v naselja s stalno naselitvijo, kot v primeru naselja Rakitna. V nekdanje počitniške hiše se tako naselijo starši, ki stanovanje v Ljubljani prepustijo potomcem. 
Karta 1 : Razvoj prebivalstva v Ljubljanski urbani regiji med leti 1991 in 2002,

Map 1: Population development in Ljubljana urban region between 1991 and 2002

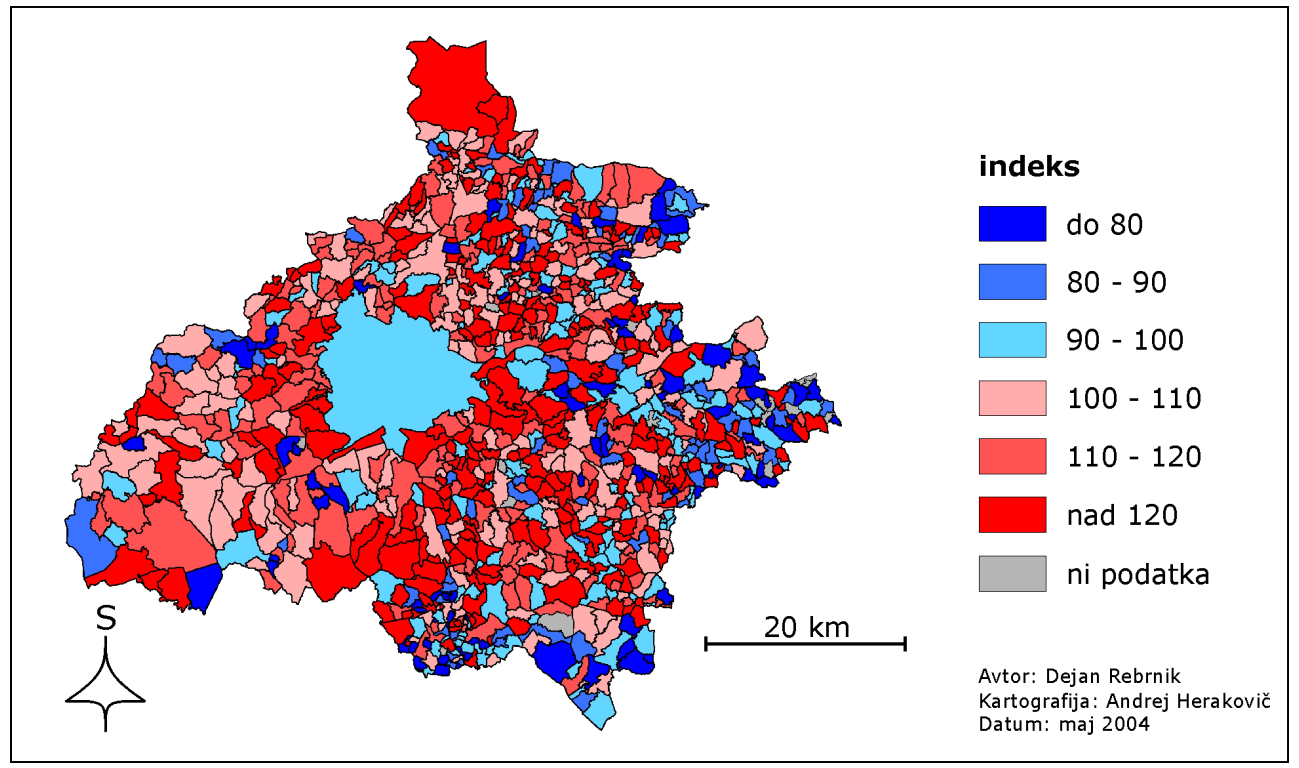

Takšno poselitev spodbujajo pomanjkanje in visoke cene stanovanj in zazidljivih zemljišč v Ljubljani in tudi v suburbaniziranih območjih. Ugotovimo torej lahko, da v Ljubljanski urbani regiji suburbanizacija prehaja v fazo periurbanizacije oziroma eksurbanizacije ali »razširjene« suburbanizacije, za katero je značilno razseljevanje prebivalstva iz gosto in sklenjeno poseljenega urbanega in suburbanega dela regije $\mathrm{v}$ redko in disperzno poseljena ruralna območja. $\mathrm{S}$ tem je regija prešla $\mathrm{v}$ novo fazo $\mathrm{v}$ urbanizacijskem ciklu.

V regiji so se tako oblikovala tri značilna območja poselitve:

Strnjeno pozidana mestna območja, ki poleg Ljubljane vključujejo še mesta in mestna naselja Vrhnika, Medvode, Domžale, Kamnik, Litija in Grosuplje. Za mesta je značilna dobra opremljenost s centralnimi dejavnostmi in koncentracija delovnih mest. Rast prebivalstva je negativna oziroma zelo nizka.

Gosto poseljeno in sklenjeno suburbanizirano obmestje, ki obroblja mesta in mestna naselja in obsega večino nižinskega dela regije. Opremljenost s centralnim dejavnostmi je pomanjkljiva. Delovnih mest je malo, kar povzroča močne tokove dnevne migracije v zaposlitvena središča, predvsem v Ljubljano. Nadaljuje se prebivalstvena rast, toda s precej nižjo stopnjo kot v osemdesetih letih. V nekaterih delih pa že prihaja do ustavitve rasti prebivalstva.

Redko in razpršeno poseljeno podeželje obsega večino hribovitega območja v regiji. Opremljenost s centralnimi dejavnostmi je zelo slaba in število delovnih mest zelo majhno. Delež agrarnega prebivalstva ostaja nadpovprečen, toda večina prebivalstva je zaposlena $\mathrm{v}$ neagrarnih dejavnostih v zaposlitvenih središčih v regiji. Zelo so značilna mešana gospodinjstva. Za zadnje desetletje je značilna hitra rast prebivalstva, predvsem na račun priseljeva- 
nja iz Ljubljane. Podeželje v regiji tako postaja predvsem bivalno okolje za prebivalstvo, ki ohranja »urbani način življenja«.

\section{RAZVOJ PREBIVALSTVA IN URBANIZACIJSKI TRENDI V LJUBLJANI PO LETU I99I}

Po letu 1991 je znotraj Ljubljanske urbane regije prišlo do pomembnih sprememb v gibanju in razporeditvi prebivalstva. Prvič se pojavi upadanje prebivalstva na celotnem območju mesta Ljubljana. Medtem ko je med leti 1981 in 1991 prebivalstvo Ljubljane naraslo za 11.000 oziroma za $4 \%$, se je med leti 1991 in 2002 število prebivalcev zmanjšalo iz 267.000 na 258.000, oziroma za 9.000 ali $3.5 \%$. Pojav upadanja števila prebivalstva, ki je bil v osemdesetih letih značilen le za mestno središče in nekatera najstarejša predmestja, se je torej okrepil in razširil tudi na ostale mestne predele. Upadanje prebivalstva tako ostane značilno za večino mestnega središča, starejša predmestja in za starejše blokovske soseske, pojavi pa se tudi v novejših stanovanjskih soseskah, kjer je bila do leta 1991 značilna rast prebivalstva.

Karta 2: Razvoj prebivalstva v Ljubljanski mestni občini med leti 1991 in 2002*

Map 2: Population development in Municipality of Ljubljana between 1991 and 2002

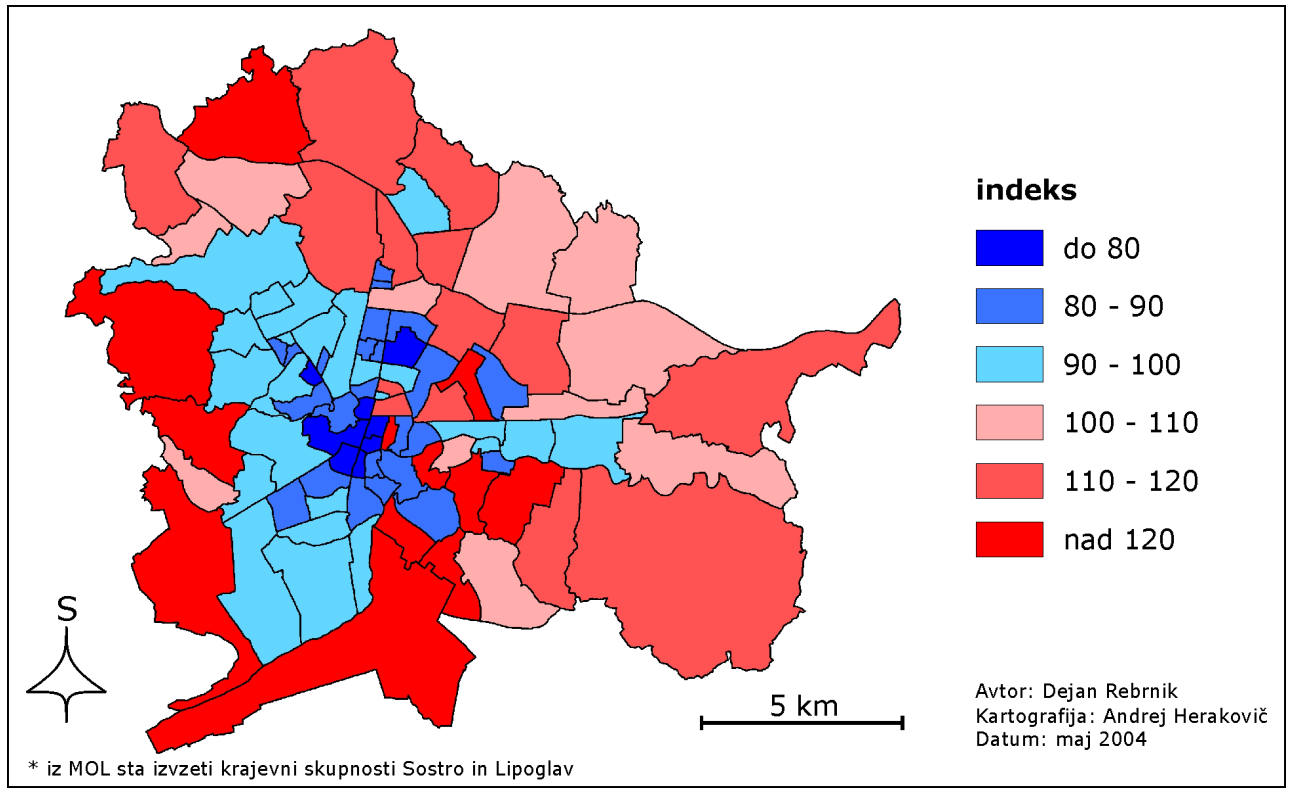

Negativni migracijski saldo je predvsem posledica odseljevanja prebivalcev v suburbanizirano obmestje ali na podeželje. Odseljuje se predvsem mlajša in srednja generacija, deloma tudi ostarelo prebivalstvo. Selitve so pogosto povezane s spremembami v družinskem polo- 
žaju. Med leti 1995 in 1999 se je iz mesta Ljubljana tako odselilo 13741 oseb, priselilo pa 7133. Negativni migracijski saldo tako znaša 6608 oseb oziroma 6.4 promila (Dolenc, 2000).

Zaradi nadpovprečnega deleža starejšega prebivalstva je višja tudi smrtnost prebivalstva. V Ljubljani je naravni prirastek tako od leta 1996 dalje negativen. Visok negativni naravni prirastek je značilen predvsem za posamezne dele mesta $\mathrm{z}$ izrazito visokim deležem ostarelega prebivalstva : stanovanjske soseske zgrajene med petdesetimi in sedemdesetimi leti in del mestnega središča. $\mathrm{V}$ teh delih mesta se število prebivalcev zmanjšuje tudi zaradi nadpovprečno visoke smrtnosti.

Na spremembe v številu in strukturi prebivalcev po posameznih delih mesta pomembno vplivajo tudi selitve znotraj mesta. $\mathrm{V}$ primerjavi z drugimi evropskimi mesti primerljive velikosti je v Ljubljani selitvena mobilnost prebivalstva znotraj mesta sicer relativno šibka, saj je v letu 1998 dosegla le 45 selitev na 1000 prebivalcev. Med leti 1995 do 1999 je bilo tako v Ljubljani zabeleženih 31770 selitev (Dolenc, 2000). V zadnjem desetletju je s sprostitvijo nepremičninskega trga in ponovno okrepljeno stanovanjsko gradnjo opaziti trend povečane bivalne mobilnosti mestnega prebivalstva. Selitve so najpogosteje povezane s spremembami v družinskem položaju prebivalstva, kot na primer poroka, rojstvo otrok, smrt ali odselitev odraslih otrok. V povezavi s tem je za Ljubljano značilno povečanje števila gospodinjstev, kljub upadanju števila prebivalstva. Povprečna velikost gospodinjstva je tako upadla iz 2.71 člana leta 1991 na 2.59 člana leta 2002. Takšen proces spodbuja stanovanjsko povpraševanje, ki ostaja v Ljubljani kljub upadanju števila prebivalcev zelo veliko.

Negativni selitveni saldo je tako značilen za večino mestnega središča in starejša stanovanjska območja, zlasti blokovske stanovanjske soseske zgrajene med petdesetimi in sedemdesetimi leti. Območja z novogradnjami, na primer mestno obrobje in manjši predeli v osrednjem delu mesta (Tabor, Poljane, Mostec, deli Bežigrada), pa imajo visok pozitiven selitveni saldo. Novogradnje in obnova stanovanjskih območij v mestnem središču oziroma na njegovem obrobju so se razmahnili zlasti po letu 1991. Ob splošnem pomanjkanju zazidljivih stavbnih zemljišč, velikem povpraševanju in visokih cenah nepremičnin je stanovanjska gradnja v osrednjem delu mesta postala zanimiva tudi za zasebne investitorje. Nova stanovanja na dobrih lokacijah so zanimiva za prebivalce z nadpovprečnimi dohodki, tako da posamezni predeli Ljubljane, kot na primer Tabor, Poljane, deli Stare Ljubljane in Zelena jama, doživljajo reurbanizacijo in gentrifikacijo.

\section{ZAKLJUČEK}

Najnovejši urbanizacijski procesi v Ljubljanski urbani regiji gredo v smer nadalje dekoncetracije prebivalstva znotraj regije. Značilna je predvsem prostorska razširitev območij suburbanizacije in razpršena urbanizacija redko poseljenih podeželskih območij v regiji. Ob tem ostaja zaposlitev osredotočena $v$ Ljubljani, kar povzroča zelo intenzivne tokove dnevne migracije zaradi zaposlitve, šolanja, oskrbe in storitev. Znotraj Ljubljane je opazen trend postopne dekoncentracije zaposlitve iz mestnega središča na obrobje in oblikovanje številnih poslovno-trgovskih območij na mestnem obrobju, zlasti ob avtocestnem obroču. Takšen prostorski razvoj mesta in celotne mestne regije spodbuja uporabo osebnega avtomobilske- 
ga prevoza, saj ostaja javni promet izrazito osredotočen na mestno središče, periferna območja $\mathrm{v}$ regiji pa so slabo dostopna $\mathrm{z}$ javnim prometom. Novejši urbanizacijski procesi $\mathrm{v}$ Ljubljanski mestni regiji, z izjemo reurbanizacije, so tako v očitnem nasprotju z deklarativnim trajnostnim prostorskim razvojem regije.

\section{Literatura}

Dolenc, D., 2000, Prostorska mobilnost prebivalstva. Ljubljana - Geografija mesta, Ljubljana, Ljubljansko geografsko društvo, 81 - 92.

Nelson A.,1992, Characterising exurbia. Journal of Planning Literature 5.

Pacione, M.,2001, Urban Geography - A Global Perspective, London in New York.

Pavlin B., Sluga G., 2000, Ljubljana kot zaposlitveno središče. Ljubljana - Geografija mesta, Ljubljana, Ljubljansko geografsko društvo, 259 - 266.

Ravbar, M., 1994, Kvaliteta življenja in kvaliteta bivalnega okolja Ljubljane : Spremljanje in vrednotenje suburbanizacijskih procesov. Urbanistični inštitut Republike Slovenije in Inštitut za geografijo, Ljubljana, 99 - 141.

Ravbar, M., 1995, Zasnova poselitve Slovenije. Inštitut za geografijo, Ljubljana.

Ravbar, M., 1997, Slovene Cities and Suburbs in Transformation. Geografski zbornik XXXVII, Ljubljana, Science Research Center of the Slovenian Academy of Sciences and Arts Geographica Institute, $65-110$.

Ravbar, M., 2002, Suburbanizacijske težnje v razvoju prebivalstva in delovnih mest v Ljubljanski mestni regiji. Geografija Ljubljane, Ljubljana, Oddelek za geografijo Filozofske fakultete Univerze v Ljubljani, 213 - 232.

Rebernik D., 1999, Prebivalstveni razvoj Ljubljane po letu 1945. Geografski vestnik 71, Ljubljana, Zveza geografskih društev Slovenije, $41-60$.

Rebernik D., 2003, Ljubljana urban region - Development Trends, Problems and Possibilities. Dela 19, Department of Geography, faculty of Arts, University of Ljubljana, 165-176.

Rebernik D., 2002, Socialnogeografska zgradba in preobrazba Ljubljane. Geografija Ljubljane, Ljubljana, Oddelek za geografijo Filozofske fakultete Univerze v Ljubljani, 83-114.

\section{POPULATION DEVELOPMENT IN LJUBLJANA URBAN REGION}

\section{Summary}

The paper presents the main characteristic of population development and urbanisation processes in Ljubljana and Ljubljana urban region. Ljubljana and its urban region had a very dynamic population development in the period after 1945. Up to the end of the seventies fast population growth was a consequence of strong immigration from rural parts of Slovenia and the rest of Yugoslavia. In the eighties and nineties deconcentration of population within the region with intense suburbanisation and depopulation of inner city and older residential neighbourhoods were the main urbanisation processes. In the second half of the 
nineties the highest population growth was recorded in dispersed rural settlements. In this way suburbanisation passed to exurbanisation and conterurbanisation. In some parts of the inner city reurbanisation and gentrification occurred.

The latest urbanisation processes in Ljubljana urban region are further deconcentration of population with dispersed urbanisation of rural parts of the region - "urban sprawl", and the beginning of reurbanisation of some parts of the inner city. Employment on the other hand remains concentrated in Ljubljana and in lesser extent in other urban employment centers. As a consequence intense daily migrations and resulting traffic are characteristic. Within Ljubljana there is a tendency of deconcetration of employment from city center to the periphery of the urban area, mostly close to highway ring that is assuring the best accessibility. New commercial, service and business centers developed along the highway ring in the last ten years, whereas in the cetral business district employment is decreasing. This kind of development is one of the main reasons for decreasing share of public transport that remains centred to the city center. The use of private car that represent almost $90 \%$ of trips in the urban area of Ljubljana is causing a lot of traffic and environmental problems and is in sharp contrast with declared sustainable development of the city and urban region. 